\title{
Prevalence of Plasmodium falciparum and non-P. falciparum infections in a highland district in Ghana, and the influence of HIV and sickle cell disease
}

\author{
Ewurama D. A. Owusu ${ }^{1,2^{*}}$, Charles A. Brown ${ }^{1}$, Martin P. Grobusch ${ }^{2,4,5}$ and Petra Mens ${ }^{2,3}$
}

\begin{abstract}
Background: In the past two decades, there has been a reported decline in malaria in Ghana and the rest of the world; yet it remains the number one cause of mortality and morbidity. Human immuno-deficiency virus (HIV) and sickle cell disease (SCD) share a common geographical space with malaria in sub-Saharan Africa and an interaction between these three conditions has been suggested. This study determined the Plasmodium falciparum and nonP. falciparum status of symptomatic and non-symptomatic residents of Mpraeso in the highlands of Kwahu-South district of Ghana based on evidence of current national decline. The influence of HIV and SCD on malaria was also determined.

Methods: Participants were 354 symptomatic patients visiting the Kwahu Government Hospital and 360 asymptomatic residents of the district capital. This cross-sectional study was conducted during the minor rainy season (October-December 2014). Rapid diagnostic tests (RDT), blood film microscopy and real-time polymerase chain reaction assessment of blood were done. Participants who tested positive with RDT were treated with artemisininbased combination therapy; and assessment of venous blood was repeated 7 days after treatment. HIV screening and haemoglobin genotyping was done. Univariate and multivariate regression analysis was used to determine the influence of SCD and HIV.
\end{abstract}

Results: Plasmodium falciparum was prevalent at 124/142 (87.3\%). Plasmodium malariae was the only non-falciparum species detected at 18/142 (12.7\%). HIV and SCD did not significantly increase odds of malaria infection. However, the use of ITN and recent anti-malarial intake significantly decreased the odds of being malaria infected by 0.45 -fold and 0.46-fold respectively.

Conclusion: Plasmodium falciparum and P. malariae infection are the prevailing species in the study area; albeit varying from the national average. HIV and SCD were not associated with the risk of having malaria.

Keywords: Falciparum, Non-falciparum, Malaria, Ghana, HIV, SCD, Highland

\section{Background}

Current indications are that malaria is on the decline in Ghana and other countries [1-5]. This might be due to

\footnotetext{
*Correspondence: edampadu@chs.edu.gh;

edampaduowusu@gmail.com

${ }^{1}$ Department of Medical Laboratory Sciences, School of Biomedical and Allied Health Sciences, College of Health Sciences, University of Ghana, Korle-bu, Accra, Ghana

Full list of author information is available at the end of the article
}

various policies that have been implemented. For instance in Ghana, the adoption of intermittent preventive treatment in pregnant women with sulfadoxine-pyrimethamine (IPTp-SP) has been shown to substantially reduce placental malaria in women in the southern part of Ghana [1]. Another reason is the countrywide free distribution of insecticide-treated bed nets (ITN) $[2,6,7]$. Also in recent years the national policy has shifted from the presumptive approach to treatment (where patients 
with clinical symptoms are treated with anti-malarials) to test-based approach, where parasitological confirmation is established with microscopy, rapid diagnostic tests (RDT) or polymerase chain reaction (PCR) $[2,4,8]$.

This significant decrease in prevalence of malaria in Ghana may result in marked changes in the current species dominance. Of the five Plasmodium species currently known to infect humans-Plasmodium falciparum, Plasmodium ovale, Plasmodium malariae, Plasmodium vivax and Plasmodium knowlesi-only the first three are documented to occur in Ghana [3]. Plasmodium falciparum is the prevailing species $(90-$ 98\%), with few P. malariae (2-9\%) and P. ovale (1\%) [4], infections found. Subspecies $P$. ovale wallikeri (variant type) and $P$. ovale curtisi (classic type), which have been identified across sub-Saharan Africa [5-8] and Asia [9], have also been observed in Northern Ghana [10].

The malaria hypothesis has shown that sickle cell disease (SCD) and malaria share a common geographical space [11]. Ghana, a malaria hyperendemic country, has about $18.8 \%$ of its population possessing the haemoglobin $\mathrm{S}(\mathrm{HbS})$ allele [12]. Human immunodeficiency virus (HIV) and SCD incidentally share the same geographical area; interactions between them have been observed [13]. On the one-hand, HIV has been shown to increase the susceptibility of individuals to malaria and the severity of malaria [14, 15]. However, severity is increased in people who do not have prior acquired partial immunity to malaria [14, 15]. The performance of anti-malarials in people living with HIV have also been shown to be reduced [14]. On the other hand, it is well known that SCD influences malaria; HbAS has been shown to confer partial malaria immunity on individuals living in malaria endemic areas [16, 17]. In contrast, homozygous $\mathrm{HbC}$ has been suggested to increase the risk of infection with $P$. malariae [16]. However, the influence of $\mathrm{HbSS}$ on increased susceptibility to malaria is unclear $[16,18]$. The authors postulate that in this study setting, where all three diseases overlap, SCD and HIV may influence infection with Plasmodium spp. The aim of this study was, therefore, to evaluate the state of $P$. falciparum and non-P. falciparum infections in a highland in the Eastern region of Ghana; and to determine the possible influence of SCD and HIV.

\section{Methods}

\section{Study site and population}

Ghana is divided into three malaria epidemiological zones; namely, northern savannah, tropical rainforest and coastal savannah and mangrove swamps [4]. The study site, Kwahu-South, is located in the tropical rainforest zone. Malaria occurs all year round, and is influenced by precipitation [19]. There are two rainy seasons in Ghana: the major rainy season (from May to June) and minor rainy season (from September to October) [19, 20].

The first group of study participants was recruited from the Kwahu Government Hospital, which is one of two district hospitals that serve communities in the entire Kwahu mountain ridge and beyond [21]. An estimated population of 230,000 people from more than 200 communities in the area of $1876 \mathrm{sq} \mathrm{km}$ receive services from this hospital [22]. The hospital has 175 beds and provides 24-hour services [22]. The Outpatient Department (OPD) serves about 250 patients daily, who are subsequently referred to the appropriate specialist department [22]. It also runs an anti-retroviral therapy (ART) clinic that attends to the health and therapeutic needs of patients living with HIV. About 65,000 confirmed malaria cases are reported in the district annually [21]. The second group of participants was recruited from the community; they were residents of the Kwahu-South district capital. Description of residents in the Kwahu-South district capital has been reported in detail elsewhere [23].

In Ghana, anyone presenting at the health facililty with axillary temperature $\geq 37.5{ }^{\circ} \mathrm{C}$ without any other symptom is suspected of malaria [24]. The current management is to first diagnose with RDT or microscopy and then treat with anti-malarial when positive [24]. Parasitological confirmation, in the absence of signs of severe disease is classified as uncomplicated malaria [24, 25]. Signs of severe/complicated malaria include unconsciousness, marked jaundice and difficulty breathing $[24,25]$. The national policy is to use oral artemisinin-based combination therapy to treat uncomplicated malaria [24]. First line drugs for uncomplicated $P$. falciparum infections are artesunateamodiaquine (AS+AQ), artemether-lumefantrine (A-L) and dihydroartemisinin-piperaquine (DHAP); the second line drug is oral quinine (QN) for 7 days [4, 24]. Intra-venous or intra-muscular anti-malarials are encouraged when severe malaria is identified, whilst waiting for laboratory results [24].

\section{Study design and participant selection}

This was a cross-sectional study, done during the minor rainy season, from October to December in 2014. Patients presenting at the OPD with an axillary temperature $\geq 37.5{ }^{\circ} \mathrm{C}$ with or without vomiting, nausea, general malaise, headaches or body aches were recruited into this study and classified as symptomatic. There was no age or sex discrimination in participant selection. Demographic data and medical history of participants were collected by trained collectors prior to sample collection, and after obtaining written or finger-stamped informed consent. Demographic data included age, sex and education whilst 
medical history included axillary temperature, symptoms, diabetes status and recent anti-malarials taken. In instances where participants could neither read nor write, questions were asked in the local language and their responses were filled in by the trained sample collectors. For children under the age of 18 years, their parents/ guardians provided responses on their behalf.

\section{Laboratory procedures}

Expert phlebotomists took venous blood from the antecubital fossa of participating patients at the hospital. This was stored in ethylenediaminetetraacetic acid (EDTA) tubes at $4{ }^{\circ} \mathrm{C}$ until processed. Participants from the community had their finger-prick capillary blood taken. Thick and thin blood smears were prepared from all samples. After air-drying, thin smears were fixed in $100 \%$ methanol. All smears were stained with $10 \%$ Giemsa which was applied to both thick and thin films for $10 \mathrm{~min}$. These were then examined by two expert microscopists. Samples were recorded as positive under 200 high powered visual fields if any amount of asexual parasites was observed per 200 white blood cells, and negative if none was observed. Discordant results were decided on by a third microscopist. A drop of each venous blood sample taken was applied to the malaria RDT First Response ${ }^{\circledR}$ Malaria Ag. Plasmodium falciparum (HRP2), to test for the presence of $P$. falciparum. Patients who tested positive for malaria, with either RDT or microscopy, were prescribed the first-line artemisinin-based combination therapy (ACT) artemether-lumefantrine by the attending physician, according to the national malaria control programme. It is a fixed-dose formulation of $20 \mathrm{mg}$ artemether and $120 \mathrm{mg}$ lumefantrine per tablet [3]. This is a 6-dose regimen taken over 3 days according to pre-defined weight bands [17]. Patients who had malaria were asked to return to the hospital 7 and 28 days after ACT treatment for re-testing with RDT and microscopy. Standard $\mathrm{Hb}$ genotyping [26] was done with about $1 \mathrm{ml}$ whole blood and categorized into HbAA (normal), HbAS (trait), HbAC (trait), HbSS (SCD) or HbSC (SCD).

Two to three drops of each blood sample was spotted onto Whatman filter paper (grade 3), dried and stored and PCR analysis done at KIT Biomedical Research Institute in Amsterdam. Boom extraction, as previously described [27], was used to obtain DNA. Real time PCR of DNA was conducted on Biorad $\mathrm{C} 1000^{\text {TM }}$ Thermal Cycler to identify pan-Plasmodium. Species identification was done, on positive samples, with nested PCR amplification of small sub-unit ribosomal RNA genes as previously described [28]. Gel electrophoresis was used to resolve PCR products with $2 \%$ agarose. The second round species-specific primers included that for detection of $P$. ovale wallikeri and $P$. ovale curtisi as described [29].

Blood samples of hospital participants were further tested for HIV using INSTANTCHEK HIV-1 + 2 rapid diagnostic test kit by EY Laboratories and Oraquick Advance Rapid HIV-1/2 antibody test by OraSure Technologies, Inc. The use of Oraquick Advance Rapid HIV-1/2 antibody test is consistent with the confirmatory testing protocol for HIV in Ghana [30].

\section{Statistical analyses}

Data was entered into Microsoft Excel and then transferred into IBM SPSS version 20 software (IBM inc, Chicago, IL, USA) for statistical analyses. Univariate and multivariate regression analysis were used in determining whether primary outcome of malaria positivity was influenced by several independent variables, after adjusting for confounders. Independent variables included sex, sickle cell status, HIV, diabetic status and anti-malarial history. The strength of association was measured by odds-ratio with a confidence interval of $95 \%$. $P$ value $\leq 0.05$ was regarded as statistically significant.

\section{Results}

The baseline medical and demographic history of participants from the OPD and community is summarized in Table 1 . In general, malaria prevalence amongst participants in the hospital was 93/354 (26.3\%); and 43/360 (11.9\%) amongst asymptomatic residents, when microscopy was used. Females in this study were $314 / 354(88.7 \%)$ and $164 / 360(45.6 \%)$ in the hospital and community, respectively. Participants from the community were equally distributed amongst the age groups. In the hospital, the majority of participants $(155 / 354 ; 43.8 \%)$ was $19-30$ years old. Majority of participants, 250/354 (70.6\%) in symptomatics and $218 / 360(60.5 \%)$ in asymptomatics had not taken any anti-malarials in the past 6 months, according to their responses in the questionnaire. About 25\% (92/354) of symptomatic patients had a haemoglobinopathy of some sort; 41/354 (11.6\%) having HbAC and 45/354 (12.7\%) having HbAS. On the other hand, 84/360 (23.3\%) of asymptomatics had $\mathrm{HbS}$ or $\mathrm{C}$. The HIV prevalence in the hospital participants was 51/354 (14.4\%) with 9/354 (2.5\%) participants testing positive for both HIV 1 and 2.

Overall, gold standard microscopy showed falciparum infections were 124/142 (87.3\%) whilst non-falciparum infections were 18/142 (12.7\%) (Table 2). Amongst the 49 participants who had non-falciparum malaria, 9 (9.7\%) were asymptomatic; only $P$. malariae was present (Table 2). No patient tested positive for $P$. ovale 
Table 1 Baseline characteristics of study participants in the district capital and the Kwahu Government Hospital

\begin{tabular}{|c|c|c|}
\hline Variable & n (\%) & \\
\hline Sex & Hospital & Community \\
\hline M & $40(11.3)$ & $196(54.4)$ \\
\hline $\mathrm{F}$ & $314(88.7)$ & $164(45.6)$ \\
\hline \multicolumn{3}{|l|}{ Age group (years) } \\
\hline$\leq 5$ & $23(6.5)$ & $60(16.7)$ \\
\hline $6-10$ & $12(3.4)$ & $60(16.7)$ \\
\hline $11-18$ & $39(11)$ & $60(16.7)$ \\
\hline $19-30$ & $155(43.8)$ & $60(16.7)$ \\
\hline $31-60$ & $105(29.7)$ & $60(16.7)$ \\
\hline Over 60 & $20(5.6)$ & $60(16.7)$ \\
\hline \multicolumn{3}{|l|}{ Recent anti-malarial intake } \\
\hline$<3$ months & $29(8.2)$ & $55(15.3)$ \\
\hline $3-6$ months & $75(21.2)$ & $87(24.2)$ \\
\hline No & $250(70.6)$ & $218(60.5)$ \\
\hline \multicolumn{3}{|l|}{ Preventive measures } \\
\hline None & $16(4.5)$ & $142(39.4)$ \\
\hline ITN & $58(16.4)$ & $10428.9)$ \\
\hline Other (mosquito spray \& coil) & $280(79.1)$ & $114(31.7)$ \\
\hline \multicolumn{3}{|l|}{ Sickling status } \\
\hline $\mathrm{HbAA}$ & $262(74)$ & $276(76.7)$ \\
\hline $\mathrm{HbAC}$ & $41(11.6)$ & $30(8.3)$ \\
\hline $\mathrm{HbAS}$ & $45(12.7)$ & $43(11.9)$ \\
\hline $\mathrm{HbSC}$ & $4(1.1)$ & $6(1.7)$ \\
\hline $\mathrm{HbSS}$ & $2(0.6)$ & $5(1.4)$ \\
\hline \multicolumn{3}{|l|}{ HIV status } \\
\hline Neg & $299(85.6)$ & \\
\hline HIV 1 & $42(11.9)$ & \\
\hline HIV 2 & $0(0)$ & \\
\hline HIV $1 \& 2$ & $9(2.5)$ & \\
\hline \multicolumn{3}{|l|}{ Malaria $^{\mathrm{a}}$} \\
\hline Negative & $261(73.7)$ & $317(88.1)$ \\
\hline Positive & $93(26.3)$ & $43(11.9)$ \\
\hline \multicolumn{3}{|l|}{ Other conditions } \\
\hline Diabetes & $13(3.7)$ & \\
\hline Pregnancy & $94(26.6)$ & \\
\hline
\end{tabular}

${ }^{a}$ Malaria was diagnosed with microscopy

curtisi, $P$. ovale wallikeri or $P$. vivax. In general, malaria was prevalent amongst participants with the normal HbAA allele. The normal $\mathrm{Hb}$ allele (AA) was found in 86/124 (69.4\%) participants with falciparum malaria; and in $11 / 18(61.1 \%)$ of participants with non-falciparum malaria. In both symptomatics and asymptomatics, malaria was prevalent in participants who had not taken anti-malarials recently (Table 2 ). Table 3 summarizes the factors that are independently associated with the risk of symptomatic Plasmodium infection. History of recent anti-malarials taken had a significant 0.46 -fold decrease in odds of malaria for both univariate and multivariate); the use of ITN showed a significant 0.45 -fold decrease in odds for malaria. Data and anyalysis for this study may be found in supplementary file (Additional file 1).

\section{Discussion}

Malaria prevalence and determinants as well as prevailing species in this highland of Ghana varied from the published prevalence of malaria in that administrative region of Ghana. This might be because of the heterogeneous nature of malaria transmission in the country. The prevalence in this study was $3.2 \%$ lower than prevalence published in the national survey [31]. Only two Plasmodium spp. out of the known three prevailed in this study area. $P$. ovale which occurs in $0.15 \%$ of known infections in Ghana [24], and persists in the two forms (P. ovale curtisi and $P$. ovale wallikeri) in different parts of the country [10], was absent in this area. P. vivax was not detected in this area. HIV and SCD did not influence malaria in this particular study.

Unlike studies done elsewhere in the country [10, 32], there were no $P$. ovale curtisi or $P$. ovale wallikeri infections in this study. Both $P$. ovale curtisi and $P$. ovale wallikeri have been found to circulate in the population in Ashanti region [10]; whilst $P$. ovale wallikeri was diagnosed in a foreign visitor to the country who visited different regions in the country [32]. Even though the occurrence of falciparum malaria was slightly lower than the Ghana national prevalence of 90-98\% [4], P. malariae in this study was much higher at $12.7 \%$ compared to that of the national prevalence of 2-9\% [4]. These differences may be attributed to the altitude and climate of this forest ecological zone. In other African countries, increase in altitude has been known to reduce malaria prevalence [33, 34]. Malaria transmission in Ghana is heterogenous; previous studies have shown villages in close proximity in another highland area of Ghana to be extremely heterogenous [35]. In this study, however, malaria prevalence and transmission dynamics of neighbouring towns and villages were not available for comparison. Yet heterogeneity was evident when findings in this study were compared with national prevalence rates.

PCR testing of malaria positive patients 7 days post treatment indicated parasite clearance in 80 out of 93 samples. A previous study in that area showed residents combined anti-malarials with local herbal preparations when treating malaria [18], and this might be the reason for the 13 uncleared parasite samples in this study. Herbal medicine has been known to negatively influence malaria parasite clearance [30]. Even though uncleared parasites might not influence subsequent incidence of clinical episodes [30], they can contribute to parasite reservoirs which are very important in malaria transmission. 
Table 2 Comparison of falciparum and non-falciparum malaria in asymptomatic and symptomatic participants, using the current gold standard in Ghana, microscopy

\begin{tabular}{|c|c|c|c|c|}
\hline & \multicolumn{2}{|c|}{ Falciparum, n (\%) } & \multicolumn{2}{|c|}{ Non-falciparum, n (\%) } \\
\hline & Symptomatic & Asymptomatic & Symptomatic & Asymptomatic \\
\hline & Day 1 & & Day 1 & \\
\hline \multirow[t]{4}{*}{ Plasmodium spp. } & $84(90.3)$ & $40(81.6)$ & P. malariae, 9 (9.7) & $9(18.4)$ \\
\hline & & & P. ovale curtisi, $0(0)$ & $0(0)$ \\
\hline & & & P. ovale wallikeri, $0(0)$ & $0(0)$ \\
\hline & & & P. vivax, $0(0)$ & $0(0)$ \\
\hline \multirow[t]{2}{*}{ Species dominance } & $124(87.3)$ & & $18(12.7)$ & \\
\hline & Day 8 & & Day 8 & \\
\hline \multirow[t]{3}{*}{ Plasmodium spp. } & $3(3.2)$ & & P. malariae, 7 (7.5) & \\
\hline & \multicolumn{2}{|c|}{ Falciparum infection } & \multicolumn{2}{|c|}{ Non-falciparum infection } \\
\hline & Symptomatic & Asymptomatic & Symptomatic & Asymptomatic \\
\hline \multicolumn{5}{|l|}{ Sex } \\
\hline M & $10(11.9)$ & $21(52.5)$ & $9(100)$ & $3(33.3)$ \\
\hline $\mathrm{F}$ & $74(88.1)$ & $19(47.5)$ & $0(0)$ & $6(66.7)$ \\
\hline \multicolumn{5}{|l|}{ Age group (years) } \\
\hline$\leq 5$ & $3(3.6)$ & $7(17.5)$ & $0(0)$ & $1(11.1)$ \\
\hline $6-10$ & $4(4.8)$ & $9(22.5)$ & $0(0)$ & $0(0)$ \\
\hline $11-18$ & $17(20.2)$ & $10(25)$ & $4(44.4)$ & $4(44.4)$ \\
\hline $19-30$ & $37(44.0)$ & $6(15)$ & $5(55.6)$ & $0(0)$ \\
\hline $31-60$ & $20(23.8)$ & $5(12.5)$ & $0(0)$ & $1(11.1)$ \\
\hline Over 60 & $3(3.6)$ & $3(7.5)$ & $0(0)$ & $3(33.3)$ \\
\hline \multicolumn{5}{|l|}{ Sickling status } \\
\hline $\mathrm{Hb} \mathrm{AA}$ & $64(76.2)$ & $22(55)$ & $5(55.6)$ & $6(66.7)$ \\
\hline $\mathrm{Hb}$ AS & $9(10.7)$ & $12(30)$ & $2(22.2)$ & $0(0)$ \\
\hline $\mathrm{Hb} \mathrm{AC}$ & 10 (11.9) & $6(15)$ & $2(22.2)$ & $3(33.3)$ \\
\hline $\mathrm{Hb}$ SS & $1(1.2)$ & $0(0)$ & $0(0)$ & $0(0)$ \\
\hline $\mathrm{Hb} \mathrm{SC}$ & $0(0)$ & $0(0)$ & $0(0)$ & $0(0)$ \\
\hline \multicolumn{5}{|c|}{ Recent anti-malarial intake } \\
\hline$<3$ months ago & $5(6)$ & $3(7.5)$ & $1(11.1)$ & $3(33.3)$ \\
\hline 3-6 months ago & $11(13.1)$ & $7(17.5)$ & $2(22.2)$ & $2(22.2)$ \\
\hline None & $68(26.9)$ & $30(75)$ & $6(66.7)$ & $4(44.5)$ \\
\hline \multicolumn{5}{|l|}{ HIV } \\
\hline HIV 1 & $13(15.5)$ & $0(0)$ & $0(0)$ & $0(0)$ \\
\hline HIV 2 & $0(0)$ & $0(0)$ & $0(0)$ & $0(0)$ \\
\hline HIV $1 \& 2$ & $2(2.2)$ & $0(0)$ & $0(0)$ & $0(0)$ \\
\hline Negative & $69(82.1)$ & $40(100)$ & $9(100)$ & $9(100)$ \\
\hline \multicolumn{5}{|l|}{ Diabetes } \\
\hline Positive & $3(23.1)$ & $0(0)$ & $0(0)$ & $0(0)$ \\
\hline Negative & 81 (76.9) & $40(100)$ & $9(100)$ & $9(100)$ \\
\hline \multicolumn{5}{|l|}{ Pregnancy } \\
\hline Positive & $17(20.2)$ & $0(0)$ & $4(44.4)$ & $0(0)$ \\
\hline Negative & $67(79.8)$ & $40(100)$ & $5(65.6)$ & $9(100)$ \\
\hline
\end{tabular}

The persistence of sub-microscopic parasites is therefore a cause for concern and warrants further investigation.

Univariate and multivariate regression analysis of the risk of having malaria in symptomatic participants showed that HIV status and sickling status did not cause any significant increase or decrease in risk, even though 14.4 and $17.7 \%$ of participants carried the $\mathrm{HbS}$ allele and had HIV respectively. In this study neither HbSS 
Table 3 Univariate and multivariate regression analyses of predictor variables for $P$. falciparum and $P$. $m a$ ariae infection

\begin{tabular}{|c|c|c|c|}
\hline Variable & n (\%) & $\begin{array}{l}\text { Univariate analysis } \\
\text { Odds ratio }(\mathrm{Cl}), \mathrm{P} \text { value }\end{array}$ & $\begin{array}{l}\text { Multivariate analysis } \\
\text { Odds ratio }(\mathrm{Cl}), \mathrm{P} \text { value }\end{array}$ \\
\hline P. falciparum positive & $84(23.7)$ & & \\
\hline \multicolumn{4}{|l|}{ SCD } \\
\hline AA & $262(74)$ & 1 & 1 \\
\hline$A C$ & $41(11.6)$ & $1.0(0.46-2.15), 0.99$ & $0.97(0.45-0.10), 0.93$ \\
\hline AS & $45(12.7)$ & 0.77 (0.35-1.69), 0.52 & $0.70(0.32-1.55), 0.38$ \\
\hline SS & $2(0.6)$ & $3.09(0.19-50.17), 0.43$ & $2.25(0.11-45.85), 0.60$ \\
\hline \multicolumn{4}{|l|}{ HIV } \\
\hline Negative & $299(85.6)$ & 1 & 1 \\
\hline HIV 1 & $42(11.9)$ & $1.49(0.74-3.03), 0.27$ & $1.33(0.64-2.78), 0.45$ \\
\hline HIV $1 \& 2$ & $9(2.5)$ & $0.95(0.95-0.19), 0.95$ & $0.93(0.19-4.67), 0.93$ \\
\hline \multicolumn{4}{|l|}{ Diabetes } \\
\hline Negative & $341(96.3)$ & 1 & 1 \\
\hline Positive & $13(3.7)$ & $0.96(0.26-3.58), 0.96$ & $0.83(0.22-3.15), 0.78$ \\
\hline \multicolumn{4}{|l|}{ Recent anti-malarial intake } \\
\hline None & $250(70.6)$ & 1 & 1 \\
\hline $3-6$ months ago & $75(21.2)$ & $0.46(0.23-0.92), 0.03^{*}$ & $0.46(0.23-0.92), 0.03^{*}$ \\
\hline$<3$ months ago & $29(8.2)$ & $0.56(0.21-1.52), 0.25$ & $0.50(0.18-1.44), 0.20$ \\
\hline \multicolumn{4}{|l|}{ Preventive measures } \\
\hline None & $16(4.5)$ & 1 & 1 \\
\hline ITN & $58(16.4)$ & $0.45(0.27-0.99), 0.04^{*}$ & $0.45(0.27-0.99), 0.04^{*}$ \\
\hline Other (mosquito spray \& coil) & $280(79.1)$ & $1.58(0.25-5.48), 0.63$ & $1.39(0.17-5.23), 0.45$ \\
\hline \multicolumn{4}{|l|}{ Sex } \\
\hline $\mathrm{F}$ & $314(88.7)$ & 1 & 1 \\
\hline M & $40(11.3)$ & $1.08(0.51-2.31), 0.84$ & $1.23(0.53-2.82), 0.63$ \\
\hline
\end{tabular}

* Statistically significant with $P$ value $\leq 0.05$

nor HbAC showed any influence on malaria; other studies have also been unable to show a clear relationship between them [16, 18, 36]. Whilst certain studies have shown decreased risk for malaria in people with $\mathrm{HbSS}$ $[37,38]$, others have shown no difference between HbSS allele and HbAA where malaria risk is concerned [16, 18, 36]. Also, heterozygous $\mathrm{HbAC}$ has not been found to influence malaria in some studies [16], yet some studies have shown malaria to be reduced in people with $\mathrm{HbAC}$ [23]. The risk for malaria in this study was also not influenced by HIV, unlike previous studies which have suggested HIV increases risk for malaria [14, 15]. However, malaria risk was reduced when participant-reported recent anti-malarials intake was 3-6 months prior to study. The use of ITN also significantly reduced odds of malaria by 0.46 -fold and 0.45 -fold respectively. This is in agreement with the current knowledge that the use of ITNs are highly effective at preventing mosquito bites much better than the mosquito coils and sprays $[39,40]$.

Despite the Ghana national policy on intermittent preventive treatment in pregnancy (IPTp), which advocates the administration of sulfadoxine-pyrimethamine at monthly intervals after 16 weeks [24], 22.3\% of pregnant women (gestation $>20$ weeks) included in this study had malaria. They constituted $22.6 \%$ of the malaria positives. More than half of the pregnant women with malaria $(14 / 21)$ had not taken any anti-malarials in the last 6 months. This could be due to low or late attendance of antenatal clinics in rural areas $[41,42]$, regardless of provision of free medical care for pregnant women under the National Health Insurance Scheme [41]. Another possible reason is the availability of poor quality sulfadoxinepyrimethamine; some SP drugs on the Ghanaian market have been found to be of low quality. A recent study found 2 out of 3 SP drugs given at hospitals in the Central region of Ghana to pregnant women failed the drug dissolution test, even though they contained the active ingredient [43]. This means that the amount of the drug that was able to dissolve within a particular period and be available for absorption in the body was very low; the drugs were therefore not effective [43]. Drop-out rates for IPTp in pregnant women in Ghana have been attributed to shortage of the drugs, unavailability of water to take the drugs with when they are dispensed, and the attitude 
of the provider [42]. All of these are possible reasons for the results in this study.

Nonetheless malaria and malaria-related deaths have declined in the past 6 years [1, 44-47]. This has been attributed to the intensified efforts to eradicate malaria through the Ghana National Malaria Control Programme.

This study had certain limitations. Firstly, the study sample was small and therefore may not have been adequately sized to accurately measure local Plasmodium species prevalence and HIV status of all participants. Participants in the hospitals were more willing to have their HIV status determined; no one in the community aspect of the study agreed to the test. Thus, the absence of statistical findings in this study may not necessarily mean the absence of parasites or correlations, and larger cohort studies are therefore needed. Secondly, even though majority of patients returned for the first follow-up, none returned for the second. This prevented information on subsequent parasite clearance from being obtained. Thirdly, this study was done during the minor rainy season. An extension of the study to include both major and minor rainy seasons would have provided a clearer interpretation of the influence of rainy seasons on malaria.

\section{Conclusion}

Plasmodium spp. type and prevalence in this study area varies from the other regions in Ghana. The high prevalence of the $\mathrm{HbS}$ allele in the study population did not significantly influence malaria; neither did HIV. Nonetheless, further large-scale studies are necessary to identify possible influence of SCD and HIV as has been suggested to occur elsewhere.

\section{Additional file}

Additional file 1. The data analysis of malaria symptomatic and asymptomatic participants in this study.

\section{Authors' contributions}

The study was conceived and designed by EDAO, MPG and PM. EDAO, CB, MPG and PM contributed to acquisition, analysis and interpretation of data The first draft of the article was written by EDAO. MPG, PM and CB critically revised it for important intellectual content. All authors read and approved the final manuscript.

\section{Author details}

1 Department of Medical Laboratory Sciences, School of Biomedical and Allied Health Sciences, College of Health Sciences, University of Ghana, Korle-bu, Accra, Ghana. ${ }^{2}$ Center of Tropical Medicine and Travel Medicine, Department of Infectious Diseases, Division of Internal Medicine, Academic Medical Centre, University of Amsterdam, Amsterdam, The Netherlands. ${ }^{3}$ Department of Medical Microbiology, Clinical Parasitology, Division of Laboratory Specialisms, Academic Medical Centre, University of Amsterdam, Amsterdam, The Netherlands. ${ }^{4}$ Centre de Recherches Médicales de Lambaréné (CERMEL),
Hôpital Albert Schweitzer, Lambaréné, Gabon. ${ }^{5}$ Institute of Tropical Medicine, University of Tübingen, Tübingen, Germany.

\section{Acknowledgements}

The Medical Superintendent, staff of the Out Patients' Department, as well as the staff of the Medical Laboratory Department of the Kwahu Government Hospital were exceptionally helpful in the data collection and analysis in this study, and for that, we are immensely grateful. The contribution of Inge Versteeg, Laura de Bes and Gerard I Schoone (Department of Parasitology), as well as Sarah Menting (TB research group) of KIT Biomedical Research Institute, Amsterdam, the Netherlands, in the PCR analysis of this study, is very much appreciated.

\section{Competing interests}

The authors declare that they have no competing interests.

\section{Availability of data and materials}

All data generated or analysed during this study are included in this published article [and its supplementary information files].

\section{Consent for publications}

The details, image or videos relating to individual participants were not used in this study.

\section{Ethics approval and consent to participate}

The Ghana Health Service Ethics Review Committee (GHS-ERC: 08/07/13) and the Noguchi Institutional Review Board (NMIMR-IRB CPN 067/13-14) granted ethical clearance for this study in accordance with the Declaration of Helsinki. For the symptomatic study, additional permission was sought from the Medical Superintendent of the hospital before commencement of the study. Informed consent to participate was obtained from each participant before each sample was taken, and in the case of minors their parents/guardians provided it.

\section{Funding}

This research did not receive any specific grant from funding agencies in the public, commercial, or not-for-profit sectors.

\section{Publisher's Note}

Springer Nature remains neutral with regard to jurisdictional claims in published maps and institutional affiliations.

Received: 8 September 2016 Accepted: 18 April 2017

Published online: 24 April 2017

\section{References}

1. Hommerich L, von Oertzen C, Bedu-Addo G, Holmberg V, Acquah PA, Eggelte TA, et al. Decline of placental malaria in southern Ghana after the implementation of intermittent preventive treatment in pregnancy. Malar J. 2007;6:144.

2. Lengeler C. Insecticide-treated bed nets and curtains for preventing malaria. Cochrane Database Syst Rev. 2004;2:CD000363.

3. $\mathrm{MOH}$. Anti-malaria drug policy for Ghana. 2014. http://www.ghanahealthservice.org/downloads/GHS_Antimalaria_drug_policy.pdf. Accessed 12 Nov 2016.

4. DFID. Malaria: country profiles. 2011. https://www.gov.uk/government/ uploads/system/uploads/attachment data/file/67476/malaria-countryprofiles.pdf. Accessed 27 Aug 2016.

5. Fançony C, Gamboa D, Sebastião Y, Hallett R, Sutherland C, SousaFigueiredo J, et al. Various pfcrt and pfmdr1 genotypes of Plasmodium falciparum. Antimicrob Agents Chemother. 2012;56:5271-7.

6. Bauffe F, Desplans J, Fraisier C, Parzy D. Real-time PCR assay for discrimination of Plasmodium ovale curtisi and Plasmodium ovale wallikeri in the Ivory Coast and in the Comoros Islands. Malar J. 2012:11:307-15.

7. Oguike MC, Betson M, Burke M, Nolder D, Stothard JR, Kleinschmidt I, et al. Plasmodium ovale curtisi and Plasmodium ovale wallikeri circulate simultaneously in African communities. Int J Parasitol. 2011;41:677-83. 
8. Sutherland CJ, Tanomsing N, Nolder D, Oguike M, Jennison C, Pukrittayakamee $\mathrm{S}$, et al. Two nonrecombining sympatric forms of the human malaria parasite Plasmodium ovale occur globally. J Infect Dis. 2010;201:1544-50.

9. Fuehrer HP, Habler VE, Fally MA, Harl J, Starzengruber P, Swoboda P, et al. Plasmodium ovale in Bangladesh: genetic diversity and the first known evidence of the sympatric distribution of Plasmodium ovale curtisi and Plasmodium ovale wallikeri in southern Asia. Int J Parasitol. 2012;42:693-9.

10. Dinko B, Oguike MC, Larbi JA, Bousema T, Sutherland CJ, Swoboda P, et al. Persistent detection of Plasmodium falciparum, P. malariae, P. ovale curtisi and $P$. ovale wallikeri after ACT treatment of asymptomatic Ghanaian school-children. Int J Parasitol Drugs Drug Resist. 2013;3:45-50.

11. Piel FB, Patil AP, Howes RE, Nyangiri OA, Gething PW, Williams TN, et al: Global distribution of the sickle cell gene and geographical confirmation of the malaria hypothesis. Nat Commun. 2010;1:104.

12. Grosse SD, Odame I, Atrash HK, Amendah DD, Piel FB, Williams TN. Sickle cell disease in Africa: a neglected cause of early childhood mortality. Am J Prev Med. 2011:41:S398-405.

13. Owusu E DA, Visser BJ, Nagel IM, Mens PF, Grobusch MP. The interaction between sickle cell disease and HIV Infection: a systematic review. Clin Infect Dis. 15;60:612-26.

14. González R, Ataíde R, Naniche D, Menéndez C, Mayor A. HIV and malaria interactions: where do we stand? Expert Rev Anti Infect Ther. 2012;10:153-65.

15. Laufer MK, Plowe CV. The interaction between HIV and malaria in Africa. Curr Infect Dis Rep. 2007;9:47-54.

16. Danquah I, Ziniel P, Eggelte TA, Ehrhardt S, Mockenhaupt FP. Influence of haemoglobins $S$ and $C$ on predominantly asymptomatic Plasmodium infections in northern Ghana. Trans R Soc Trop Med Hyg. 2010;104:713-9.

17. Gong L, Maiteki-Sebuguzi C, Rosenthal PJ, Hubbard AE, Drakeley CJ, Dorsey $\mathrm{G}$, et al. Evidence for both innate and acquired mechanisms of protection from Plasmodium falciparum in children with sickle cell trait. Blood. 2012:119:3808-14.

18. Komba AN, Makani J, Sadarangani M, Ajala-Agbo T, Berkley JA, Newton CRJC, et al. Malaria as a cause of morbidity and mortality in children with homozygous sickle cell disease on the coast of Kenya. Clin Infect Dis. 2009;49:216-22.

19. Dery DB, Brown C, Asante KP, Adams M, Dosoo D, Amenga-Etego S, et al. Patterns and seasonality of malaria transmission in the forest-savannah transitional zones of Ghana. Malar J. 2010:9:314

20. Afari E, Appawu M, Dunyo S, Baffoe-Wilmot A, Nkrumah F. Malaria infection, morbidity and transmission in two ecological zones Southern Ghana. Afr J Health Sci. 1995;2:312-5.

21. DHMT-MOH. Kwahu-South District Health Report. 2010. p. 1-8. http:// erhd.org/cgi/erhd/hosp_atibie.php. Accessed 26 Feb 2016.

22. GHS. Kwahu Government Hospital. East Reg Health Dir. 2013. http://erhd. org/cgi/erhd/hosp_atibie.php. Accessed 26 Feb 2016.

23. Owusu EDA, Buabeng V, Dadzie S, Brown CA, Grobusch MP, Mens P. Characteristics of asymptomatic Plasmodium spp. parasitaemia in KwahuMpraeso, a malaria endemic mountainous district in Ghana, West Africa. Malar J. 2016;15:38

24. $\mathrm{MOH}$. Guidelines for case management of malaria in Ghana. 2014. http:// www.ghanahealthservice.org/downloads/GUIDELINEFORCASEMANAGEMENT.pdf. Accessed 21 Mar 2016.

25. WHO. World Malaria Report 2016. Geneva, World Health Organization. 2016 http://apps.who.int/iris/bitstr eam/10665/252038/1/9789241511711-eng.pdf?ua=1. Accessed 03 Apr 2017

26. Evans D. Haemoglobin electrophoresis on cellulose acetate using whole blood samples. J Clin Pathol. 1971;24:877-8.

27. Boom R, Sol C, Salimans M, Jansen C, Wertheim-van Dillen P, van der Noordaa J. Rapid and simple method for purification of nucleic acids. J Clin Microbiol. 1990;28:495-503.
28. Snounou G, Viriyakosola S, Zhua XP, Jarraa W, Rosariob VE, Thaithonge $\mathrm{S}$, et al. High sensitivity of detection of human malaria parasites by the use of nested polymerase chain reaction. Mol Biochem Parasitol. 1993;61:315-20.

29. Calderaro A, Piccolo G, Gorrini C, Montecchini S, Rossi S, Medici MC, et al. A new real-time PCR for the detection of Plasmodium ovale wallikeri. PLoS ONE. 2012;7:e48033.

30. Boadu R, Darko G, Nortey P, Akweongo P, Sarfo B. Assessing the sensitivity and specificity of First Response HIV-1-2 test kit with whole blood and serum samples: a cross-sectional study. AIDS Res Ther. 2016;13:9.

31. Ghana Statistical Service. Ghana Demographic and Health Survey 2014: Key indicators 2015. http://www.statsghana.gov.gh/docfiles/DHS_ Report/Ghana_DHS_2014-KIR-21_May_2015.pdf. Accessed 11 Sept 2016.

32. Tordrup D, Virenfeldt J, Andersen FF, Petersen E. Variant Plasmodium ovale isolated from a patient infected in Ghana. Malar J. 2011;10:15.

33. Balls MJ, Bødker R, Thomas CJ, Kisinza W, Msangeni HA, Lindsay SW. Effect of topography on the risk of malaria infection in the Usambara Mountains, Tanzania. Trans R Soc Trop Med Hyg. 2004:98:400-8.

34. Lindsay SW, Martens WJM. Malaria in the African highlands: past, present and future. Bull World Health Organ. 1998;1953:33-45.

35. Badu K, Brenya RC, Timmann C, Garms R, Kruppa TF. Malaria transmission intensity and dynamics of clinical malaria incidence in a mountainous forest region of Ghana. Malar World J. 2013;4:1-9.

36. Maeder MN, Rabezanahary HM, Zafindraibe NJ, Randriatiana MR, Rasamoelina T, Rakotoarivo AT, et al. Sickle-cell disease in febrile children living in a rural village of Madagascar and association with malaria and respiratory infections. BMC Hematol. 2016;16:30.

37. Aluoch JR. Higher resistance to Plasmodium falciparum infection in patients with homozygous sickle cell disease in western Kenya. Trop Med Int Health. 1997;2:568-71.

38. Patel DK, Mashon RS, Purohit P, Meher S, Dehury S, Marndi C, et al. Influence of sickle cell gene on the allelic diversity at the msp-1 locus of Plasmodium falciparum in adult patients with severe malaria. Mediterr. J Hematol Infect Dis. 2015;7:1-8.

39. Baume CA, Franca-Koh AC. Predictors of mosquito net use in Ghana. Malar J. 2011;10:265.

40. Hogarh JN, Antwi-Agyei P, Obiri-Danso K. Application of mosquito repellent coils and associated self-reported health issues in Ghana. Malar J. 2016;15:61.

41. Khan SM, Singh K. The Association between health insurance coverage and skilled birth attendance in Ghana: a national study. Matern Child Health J. 2016:20:534-41.

42. Doku DT, Zankawah MM, Adu-Gyamfi AB. Factors influencing dropout rate of intermittent preventive treatment of malaria during pregnancy. BMC Res Notes. 2016;9:460.

43. Yeboah DF, Afoakwah R, Nwaefuna EK, Verner O, Boampong JN. Quality of sulfadoxine-pyrimethamine given as antimalarial prophylaxis in pregnant women in selected health facilities in central region of Ghana. J Parasitol Res. 2016;2016:9231946.

44. GSS. Multiple Indicator Cluster Survey Ghana 2011. Ghana Stat. Serv. 2011. http://www.statsghana.gov.gh/nada/index.php/catalog/88. Accessed 12 Jan 2016.

45. Baiden F, Malm K, Bart-Plange C, Hodgson A, Chandramohan D, Webster $J$, et al. Shifting from presumptive to test-based management of malaria - technical basis and implications for malaria control in Ghana. Ghana Med J. 2014;48:112-22.

46. USAID. President's malaria initiative Ghana-malaria operational plan FY 2015. 2015. pp 1-45. http://www.pmi.gov/countries/mops/fy13/liberia_mop_fy13.pdf. Accessed 21 Sept 2016.

47. Koram KA, Owusu-Agyei S, Utz G, Binka FN, Baird JK, Hoffman SL, et al. Severe anemia in young children after high and low malaria transmission seasons in the Kassena-Nankana district of northern Ghana. Am J Trop Med Hyg. 2000;62:670-4. 